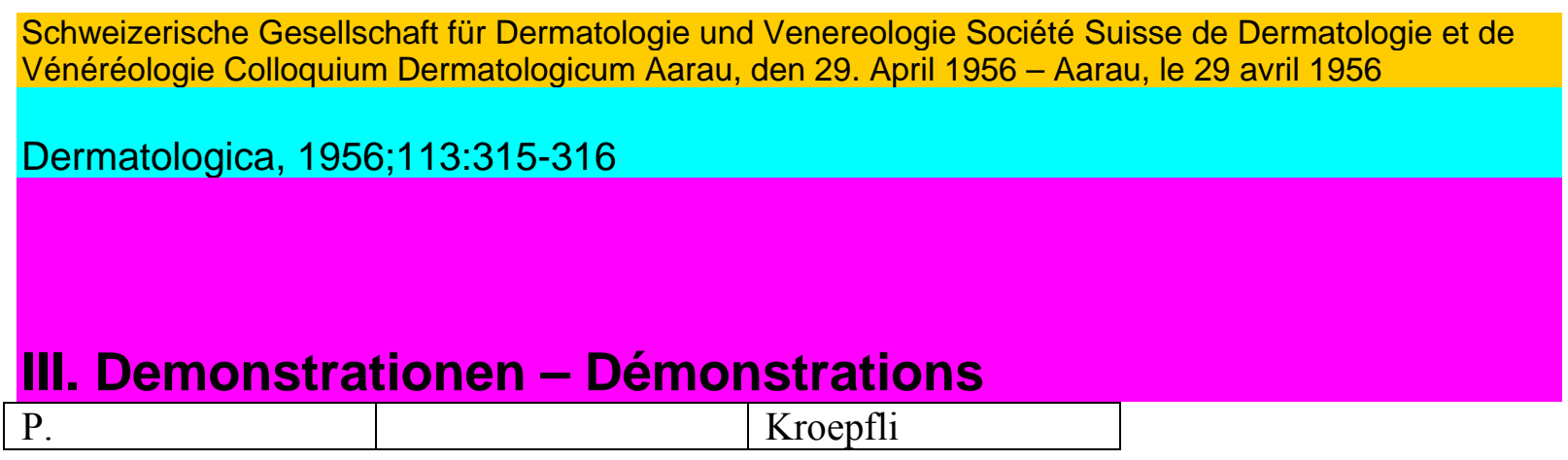

Dermatologische Universitätsklinik Basel (Prof. Dr. W. Lutz)

1. Morbus Darier:

Frau U. H., 1888: Seit etwa 1 Jahr bemerkt Patientin eine zunehmende Pig-meritierung der Haut am Halse mit Auftreten von bis linsengroßen, mit einer fest-haftenden Kruste bedeckten

Knötchen. Bei der Untersuchung finden sich gleiche Effloreszenzen in der behaarten

Schläfengegend. Klinisch bietet sich somit das Bild eines M. Darier, das durch die histologische Prüfung bestätigt wird, indeni man im Epithel mikroskopisch die typischen Lückenbildungen zusammen mit Epithel-sprossen, Hornzapfen und Corps ronds findet.

\title{
2. Melanom
}

Siebenundfünfzigjährige Patientin, Frau R. M., die angeblich vor 5 Jahren zum erstenmal eine blauverfärbte Hautstelle an der rechten Planta pedis direkt proximal der zweiten Zehe bemerkt habe. Dieser blaue Fleck sei im Verlauf der Jahre größer geworden. Im Zentrum habe sich eine warzenartige Verdickung gebildet. Wir sahen einen gut $4 \mathrm{~cm}$ im Durchmesser messenden blaubraun verfärbten, sehr unregelmäßig begrenzten Hautbezirk über der rechten Fußballe, in dessen Zentrum sich ein etwa haselnußgroßer, flach erhabener, schwammig-weich anzufühlender Tumor fand. Die histologische Untersuchung des Tumors ergab ein malignes Melanom. Das Bein wurde unterhalb des Knies amputiert.

3. Granulomatosis dísciformís chronica et progressiva ?

Frau Ae. M., 1919, zeigt einen der Stirnhaargrenze entlang verlaufenden bis seit-lich über die Schläfen reichenden etwa $2 \mathrm{~cm}$ breiten, geröteten Streifen, in dessen Bereich die Haut eine deutliche Atrophie erkennen läßt. Die Begrerizung gegen die normale Haut wird durch einen leicht erhabenen, infiltrierten Rand gebildet. Keine Schuppung, keine Einzeleffloreszenzen. Die mikroskopische Kontrolle einer Probe-exzision ergibt folgenden Befund: Unter einem deutlich verschmälerten Epithel findet sich ein lockeres, granulomatöses Infiltrat, das zur Hauptsache aus Rund-zellen und Histiozyten besteht mit Einlagerung von Fremdkòrperriesenzellen. Das histologische Bild läßt am ehesten an eine Granulomatosis disc, denken. (WaR negativ, am übrigen Körper keine weiteren Effloreszenzen.)

4. Oberßächliche, strangförmíge Phlebítíden

Fall 1: 26jähriger Medizinstudent L. F., der seit einigen Wochen am linken Vorderarm, rechten Oberschenkel und beiden Unterschenkeln das Auftreten von mehreren, 3 bis $4 \mathrm{~cm}$ langen, subkutan gelegenen Infiltraten bemerkte. Es handelt

316

Demonstrationen - Demonstrations

sich um längliche, derbe Verdickungen von der Dicke eines dünnen Bleistifts, die etwas druckdoleiit sind und über denen die Haut gut verschieblich ist. An einer Stelle ist die darüberliegende Haut leicht gerötet. Die Blutsenkungsgeschwindigkeit betrug 24/54. Im Blutbild 
fanden sich bei 9700 Leukozyten 3\% Eosinophile, 7,5\% Stabk., 7\% Monozyten, 18,5\% Lymphozyten, 64\% Segmentkernige. Klinisch chro-nische Tonsillitis. Das Bild gehört sicher zu der von Mondor als Phlébite en ficelles beschriebenen, von Favre phlébite en fil de fer und kürzlich von Braun-Falco (Derm. Wschr. 132, 27, 1955) oberflächliche, strangförmige Phlebitis genannten Krankheit. Bei der Exzision eines solchen Infiltrates fand sich auch tatsächlich erne auf kurze Strecke knotig verdickte, oberflächliche Vene, die histologisch im Lumen einen kleinen Thrombus aufwies und deren Wandung, sowohl Intima als auch äußere Schichten, enorm verdickt und mit einem entzündlichen Infiltrat durchsetzt war. Da der Patient die Tonsillektomie verweigerte, wurde eine Behandlung mit Butazolidin durchgeführt, die innert 10 Tagen zum Verschwinden der phlebitischen Veränderungen führte. Einige Wochen später wurde beim Patienten ein Bandwurm diagnostiziert.

Fall 2: 30jähriger Patient, der ebenfalls seit 2 bis 3 Wochen über dem rechten Fußrücken und über der linken Tibia unterhalb des Knies einen subkutan gelegenen, derben, etwa $3 \mathrm{~cm}$ langen, etwas druckdolenten Strang verspürte. Bei der Unter-suchung fanden wir einen weiteren Herd am linken Vorderarm. Exzision und histo-logische Kontrolle zeigten auch hier das Bild einer umschriebenen Phlebitis und Periphlebitis. Auch bei diesem Patienten Besserung der subjektiven und objektiven Symptome auf Butazolidin innert 2 Wochen.

Sammelreferate - Surveys - Revues générales

Syphilis

1. Juli 1955 bis 30. Juni 1956 Von F. WORTMANN, Basel

Allgemeínes

Beerman $r$ gibt wieder die durch seine Kommentare besonders wertvolle Ubersicht über die Syphilisliteratur vor allem des angelsächsischen Sprach-gebiets heraus, während Pílz 2 eine Zusammenstellung des uns weniger zu-gänglichen, neueren sowjet-russischen Schrifttums über die Lues veröffent-licht. Rückblickende Arbeiten erschienen von Hoffmann 3 (Aus mehr als 50jähriger Syphilisforscbung), Carleton 4 (Reminiszenzen über Diagnose und Therapie der Lues in einem New Yorker Spital um die Jahrhundertwende), 